\title{
A Modified Multiband Planar Antenna for Wireless Commnunications
}

\author{
P. Prabhu
}

Dept. of Elec.Com Engg, SRM Institute of Science and Technology, Katankulathur, Chennai, India.

Received 7 January 2018; Accepted 13 August 2018

\begin{abstract}
In this paper, a multiband rectangular planar antenna for WLAN and WiMAX, satellite applications is proposed. The proposed folded C-shaped and L-shaped meander grid is compact with dimensions of $30 \mathrm{~mm} \times 17.9 \mathrm{~mm} \times 1.6 \mathrm{~mm}$ compared to state-of-art designs. The fabrication was performed for the optimized sizes. The fabricated planar antenna was printed on both sides of an FR4 substrate and consists of the L-shaped meander grid and a C-shaped strip. The Lshaped meander grid strip is printed on the front surface of the board, while the C-shaped strip is printed on the back side of the substrate. These two strips are connected electrically without via/hole. Mutual coupling between the two strips provides broad bandwidth. The simulated and measured results indicate that antenna resonates at $3.5 \mathrm{GHz}, 5.5 \mathrm{GHz}, 8.4$ $\mathrm{GHz}$, and $10.4 \mathrm{GHz}$ for multiband applications. The measured results suggest that this design competes with existing designs with high bandwidth and minimum return loss. The measured voltage standing wave ratio of the designed antenna is less than 2 for all resonant frequencies. During the simulation and measurements, the proposed antenna was observed to have an omnidirectional radiation pattern for the entire operating frequency band. Due to its significant performance, it is suitable for multiband operations.
\end{abstract}

Keywords: Multiband antenna, folded antenna, microstrip-fed,WLAN, WiMAX and Satellite Communication

\section{Introduction}

The development of compact wireless devices has prompted the design of antennas with multiple bands to provide solutions for various communication applications. These antennas operate at different wireless standards, such as DCS-1800 (1710 MHz-1880 MHz), LTE at $2.6 \mathrm{GHz}(2570$ $\mathrm{MHz}-2640 \mathrm{MHz})$, IEEE 802.11 WLAN at $5.1 \mathrm{GHz}(5 \mathrm{GHz}-$ 5.5.875 GHz), and satellite communication C-band applications (4 GHz-8 GHz). Among the various classifications of antennas, planar antennas perform well due to their resonance behavior for more than one frequency [115]. In recent years, designs with a low profile have gained attention due to their ability to generate multiband frequencies. These antennas were developed with optimizations either regarding strips or shape. A multiband planar antenna with an L-shaped coupling, an S-shaped strip, and inverted $\mathrm{C}, \mathrm{X}$, and $\mathrm{F}$-shaped monopoles with a meandering coupling has been proposed, operating at 1.8 $\mathrm{GHz}, 2.6,3.5$, and $5.2-5.8 \mathrm{GHz}$ frequencies for LTE, GSM, UMTS, WiMAX, and WLAN operations [1]. A low-profile multiband antenna using a ferrite substrate has also been proposed. It consists of the rectangular patch with six terminating pins, a ground plane, four slots, and joining lines that resonate at frequencies of $2.4 \mathrm{GHz}, 3.5 \mathrm{GHz}$, and 3.7 $\mathrm{GHz}$ for telematics applications [2].

Multiband antennas for GSM, DCS, and LTE applications have also been suggested. It is combined by etching the four slits into the ground plane [3]. In [4], a nondirectional radiation pattern of the designed antenna can be

*E-mail address: prabhuphd1987@gmail.com

ISSN: $1791-2377$ C 2018 Eastern Macedonia and Thrace Institute of Technology. All rights reserved. doi:10.25103/jestr.115.22 achieved by inserting a double dipole array above and below the vertical plane (VP) of the substrate. The VP element used in the design has three radiating patches of dish shape. The antenna operates better in the $692-1003 \mathrm{MHz}$ and 1.9 $\mathrm{GHz}-3.21 \mathrm{GHz}$ bands. An ultra-wideband antenna for multiband frequency has also proposed. This design involves stuffing its feed portion with circular fragmented disc resonator couple of changeable sizes. The attachment of this part in the inner disc alignments and terminating copper strips permits resonating in the following frequency bands: 3.3-3.7 GHz, 5.15-5.85 GHz, and $0.25-7.75 \mathrm{GHz}$ for WiMAX, WLAN, and X-band applications, respectively [5]. A planar square-shaped, multiband, microstrip-fed antenna with a Koch fractal slot has been developed with an island fractal slot that permits operating at various resonant frequencies, such as $1.7 \mathrm{GHz}, 2.36 \mathrm{GHz}, 2.43 \mathrm{GHz}, 3.61$ $\mathrm{GHz}, 3.67 \mathrm{GHz}, 4.59 \mathrm{GHz}, 5.2 \mathrm{GHz}$, and $5.7 \mathrm{GHz}$, for wireless applications [6]. A compact, broadband planar antenna for DCS-1800, GPS, UMTS, and Wireless LAN has been proposed. It consists of a C-shaped T-strip and a 50$\mathrm{ohm}$ feed at the center part of the ground plane and resonates at four frequencies ie., $1.5 \mathrm{GHz}, 1800 \mathrm{MHz}, 2000 \mathrm{MHz}$, and $2.5 \mathrm{GHz}$. Due to its significant performance, the linearly polarized antenna can be used for GPS applications [7].

A quadrupole helical antenna has been proposed. It consists of four spiral radiating components that bring the novelty of multi-band frequencies, which is very useful for GPS and WLAN applications. In [9], dual L-shaped monopole strips are used to excite in the $2.6 \mathrm{GHz}, 3.5 \mathrm{GHz}$, and $5.5 \mathrm{GHz}$ frequecny bands in WiMAX applications.

Several multi-band antennas are presented in the report. They show the characteristics of planar/non-planar antennas and use holes to form electrical contacts between the two conductors, and the existing works also compete with each 
other. However, it has disadvantages include inadequate compaction, insufficient bandwidth, and the presence of excitation methods. To overcome these deficiencies, a modified compact multi-frequency planar antenna with a size of $30 \mathrm{~mm} \times 17.9 \mathrm{~mm} \times 1.6 \mathrm{~mm}$ was proposed, and a wrinkled arrangement having C-shaped and L-shaped meander grid was proposed.

Table 1. Comparison of the Existing Antenna Characteristics.

\begin{tabular}{l|l|l|l}
\hline Reference & $\begin{array}{l}\text { Dimensions } \\
(\mathbf{m m})\end{array}$ & $\begin{array}{l}\text { BW } \\
(\mathbf{G H z})\end{array}$ & $\begin{array}{l}\text { Gain } \\
(\mathbf{d B i})\end{array}$ \\
\hline Ref [1] & $110 \times 65 \times 2.2$ & 2 & $3-6$ \\
Ref [2] & $80 \times 70 \times 2.0$ & $0.1-0.2$ & $2.7-4.5$ \\
Ref [3] & $60 \times 80 \times 0.8$ & $0.5-2.1$ & $4.6-5.6$ \\
Ref [4] & $117 \times 117 \times 2.2$ & $0.3-0.8$ & $3-4$ \\
Ref [5] & $65 \times 40 \times 0.8$ & 0.625 & $1-7$ \\
Ref [6] & $70 \times 70$ & $0-0.470$ & $1-7.8$ \\
Ref [7] & $69 \times 18.1$ & 1.10 & $1.48-$ \\
& & & 2.45 \\
Ref [8] & $16.3 \times 5.2$ & $0-0.5$ & $0-3$ \\
Ref [9] & $25 \times 10 \times 16 \times 10$ & $0.2-1.08$ & $2.5-8.0$ \\
Ref [10] & $25 \times 30$ & $0.2-1.4$ & $3.5-5.5$ \\
\hline Proposed & $\mathbf{3 0} \times \mathbf{1 7 . 9} \times \mathbf{1 . 6}$ & $\mathbf{3 - 1 1}$ & $\mathbf{4 - 4 . 8}$ \\
\hline
\end{tabular}

\section{Antenna Design}

The suggested compact multiband antenna structure is depicted in Figure 1. The multiband planar antenna printed on the FR4 substrate that has a thickness of $1.6 \mathrm{~mm}$ and a dielectric constant of 4.4 , which contributes to a thin antenna structure. This multi-band compact antenna consists of the L-shaped twisted strip and C-shaped strip. An L-shaped twisted strip is printed on the front side of the substrate, and a C-shaped strip is placed on the rear side of the substrate. In traditional designs, holes were used to connect the two conductors to the sides. It complicates design since it requires the use of coaxial feeds for mobile applications. Thus, a direct electrical connection between the ground plane and the radiator strip improves design performance.

The folded structure created through the upper portion of the L-shaped bent strip is adapted to the region enclosed by the top portion of the C-shaped strip. The lower part of the L-shaped strip overlies the lower portion of the C-shaped strip to form a double strip structure. The mutual coupling is obtained between the two strips by overlaying the two strips. The L-shaped zigzag band is linked to the C-shaped strip for WiMAX-3500 MHz / WLAN-5500 MHz / satellite 8400 $\mathrm{MHz} / 10400 \mathrm{MHz}$ in the $3.4-12 \mathrm{GHz}$ bands. The dimensions of the $\mathrm{L}$ and $\mathrm{C}$-shaped strips are approximately equal to a quarter wavelength.

The folded structure helps to realize the compactness of the proposed configuration. The length of the ground plane plays a vital role in multi-band antenna devices such as mobile handsets. As a result, various ground dimensions were optimized, and the best performance was obtained in the size of $30 \mathrm{~mm} \times 17.9 \mathrm{~mm}$. Table. 2 presents the optimized size of the suggested multiband configuration. Antenna performance is further optimized by adjusting the height of the upper portion of the L-shaped bent strip and the C-shaped strip.

\section{2.a) Design Formulas:}

The patch width of antenna determined by applying the formula as shown in below,

$$
W=\frac{c_{o}}{2 f_{r}} \sqrt{\frac{2}{\varepsilon_{r}+1}}
$$

Effective refractive index:

$$
\varepsilon_{r e f f}=\frac{\varepsilon_{r}+1}{2}+\frac{\varepsilon_{r}-1}{2}\left[1+12 \frac{h}{w}\right]^{-1 / 2}, w / h>1
$$

Calculation of the Effective length

$$
L_{e f f}=\frac{c}{2 f_{o} \sqrt{\varepsilon_{e f f}}}
$$

The patch length of antenna determined by applying the formula as mentioned below,

$$
L=\frac{c_{o}}{2 f \sqrt{\varepsilon_{r e f f}}}-2 \Delta L
$$

Ground length $(\mathrm{Lg})$ and width $(\mathrm{Wg})$ is as follows,

$$
L_{g}=6 h+L
$$

$$
W_{g}=6 h+W
$$

Table 2. Optimized dimensions of the Proposed Antenna.

\begin{tabular}{l|l|l|l}
\hline Parameter & $\begin{array}{l}\text { Dimensions } \\
(\mathbf{m m})\end{array}$ & Parameter & $\begin{array}{l}\text { Dimensions } \\
(\mathbf{m m})\end{array}$ \\
\hline $\mathrm{H}_{\mathrm{T}}$ & 30 & $\mathrm{~W}_{\mathrm{T}}$ & 17.9 \\
\hline $\mathrm{h}_{1}$ & 4.2 & $\mathrm{w}_{1}$ & 17.9 \\
\hline $\mathrm{h}_{2}$ & 2.4 & $\mathrm{~W}_{2}$ & 14 \\
\hline $\mathrm{h}_{3}$ & 5.2 & $\mathrm{~W}_{3}$ & 1.8 \\
\hline $\mathrm{h}_{4}$ & 1.2 & $\mathrm{w}_{4}$ & 0.75 \\
\hline $\mathrm{h}_{5}$ & 0.6 & $\mathrm{~W}_{5}$ & 0.75 \\
\hline $\mathrm{h}_{6}$ & 1.8 & $\mathrm{w}_{6}$ & 8 \\
\hline $\mathrm{h}_{7}$ & 22 & $\mathrm{w}_{7}$ & 1.8 \\
\hline $\mathrm{h}_{8}$ & 0.8 & $\mathrm{w}_{8}$ & 17.3 \\
\hline $\mathrm{H}_{\mathrm{g}}$ & 23 & $\mathrm{~W}_{\mathrm{g}}$ & 17.9 \\
\hline $\mathrm{h}_{9}$ & 0.6 & & \\
\hline $\mathrm{H}$ & 6.8 & & \\
\hline
\end{tabular}

\section{Results And Discussions}

The proposed antenna structure with optimized dimensions was simulated by the Advanced Design System (ADS), and experimental interpretations are carried out by attaching antenna in a keysight N9926A VNA.

Figure 2 and (a) 2 (b) are shows photo of fornt and back side of a fabricated multi-band antenna. The antenna is fabricated on the easily available FR4 substrate with a width of $1.6 \mathrm{~mm}$. 


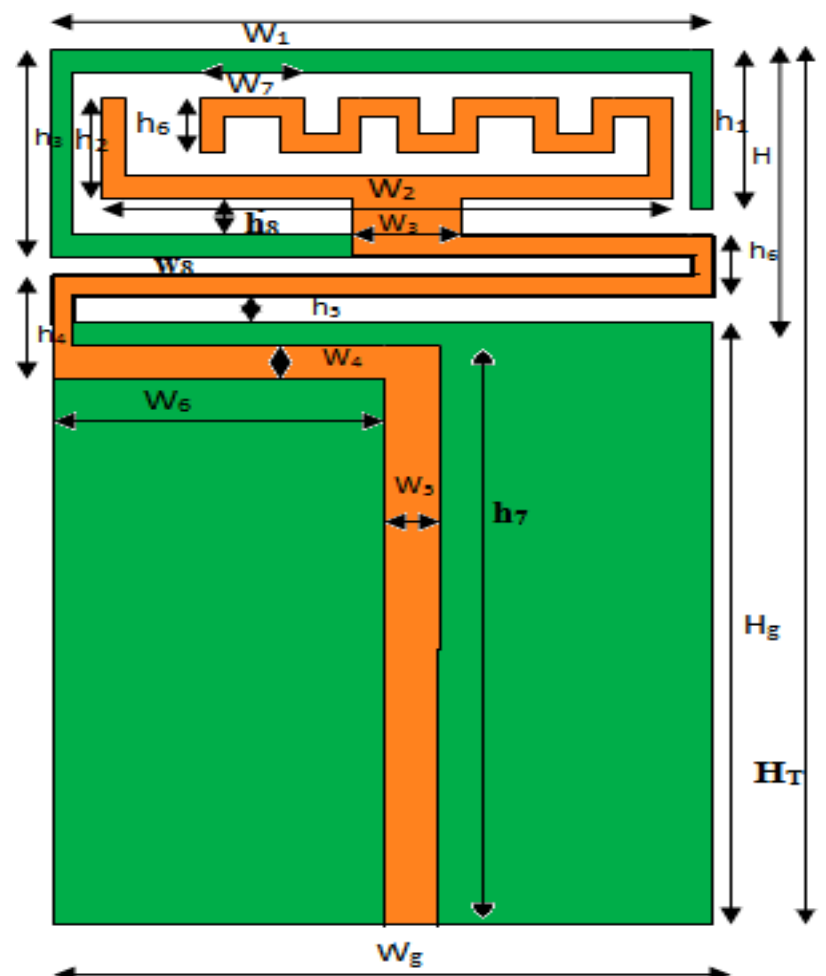

Fig. 1. Proposed Antenna Structure With C-strip and L-meander shaped Grid.

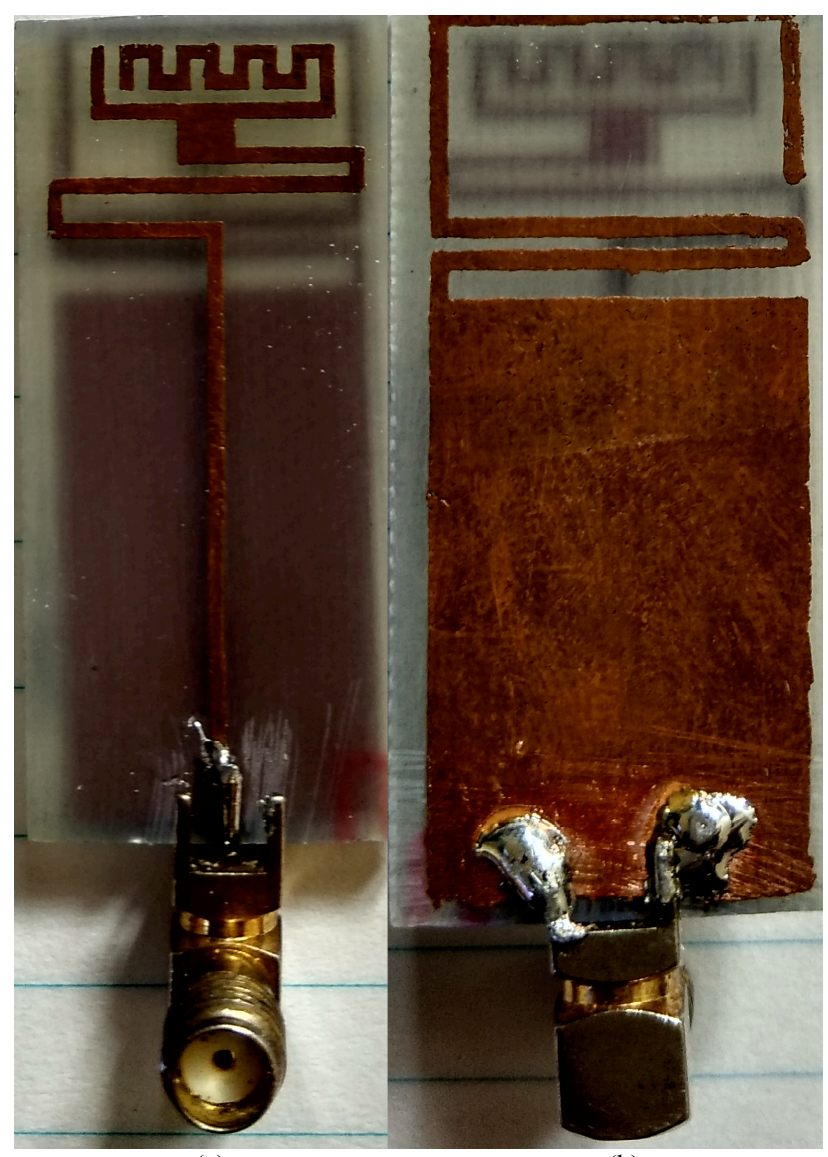

(a)

(b)

Fig. 2 (a) The Front side of Prototype (b) Back Side of Prototype.

The optimization began with a length of the ground plane, and height $(\mathrm{H})$ of the folded configuration (C-shaped and L-shaped ). The optimization of the ' $\mathrm{H}$ ' stimulates different resonant frequencies. Besides helping to achieve coupling between the two strips, which provides the broad bandwidth. The folded structure helps to produce a thin configuration, as well as optimization of ground plane length creates impact in radiation characteristics. The simulated S11 parameters of the multi-band antenna at three different ground plane width $(\mathrm{Wg})$ such as $\mathrm{Wg}=30 \mathrm{~mm}, \mathrm{Wg}=25 \mathrm{~mm}$ and $\mathrm{Wg}=17.9 \mathrm{~mm}$ and different height $(\mathrm{H})(8.6 \mathrm{~mm}, 6.8$ $\mathrm{mm}$ and $5.5 \mathrm{~mm}$ ) is displayed in Figure 3. The fringing effect varies based on the thickness of the substrate so substrate thickness also optimized. Figure 4 presents the simulation results of the antenna with various substrate thickness, specifically, $0.8 \mathrm{~mm}, 1.2 \mathrm{~mm}$ and $1.6 \mathrm{~mm}$. Also, Figure 5 represents the simulation (S11) results of the antenna with different types of substrate, namely, FR4, Arlon and Rogers.

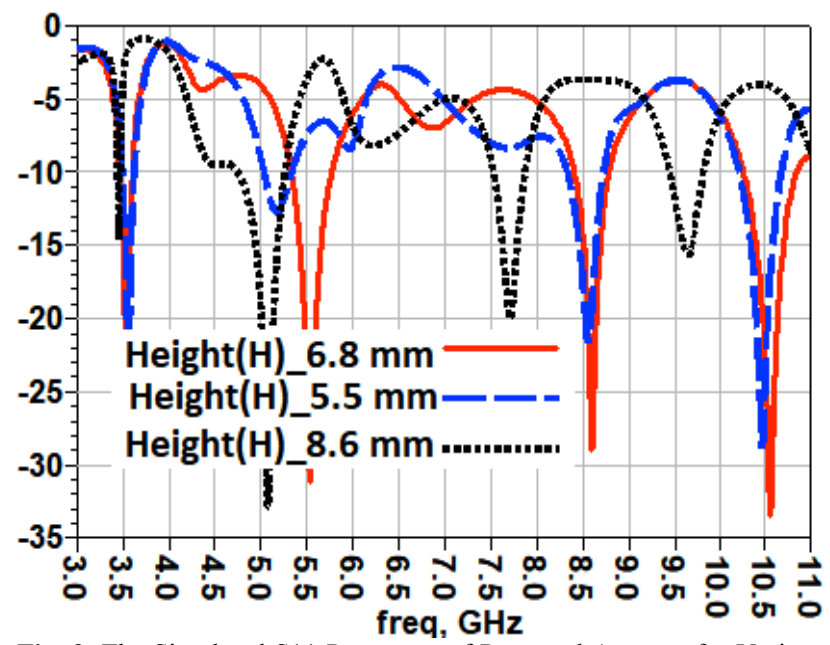

Fig. 3. The Simulated S11-Parameter of Proposed Antenna for Various Ground Plane Dimension and Height $(\mathrm{H})$.

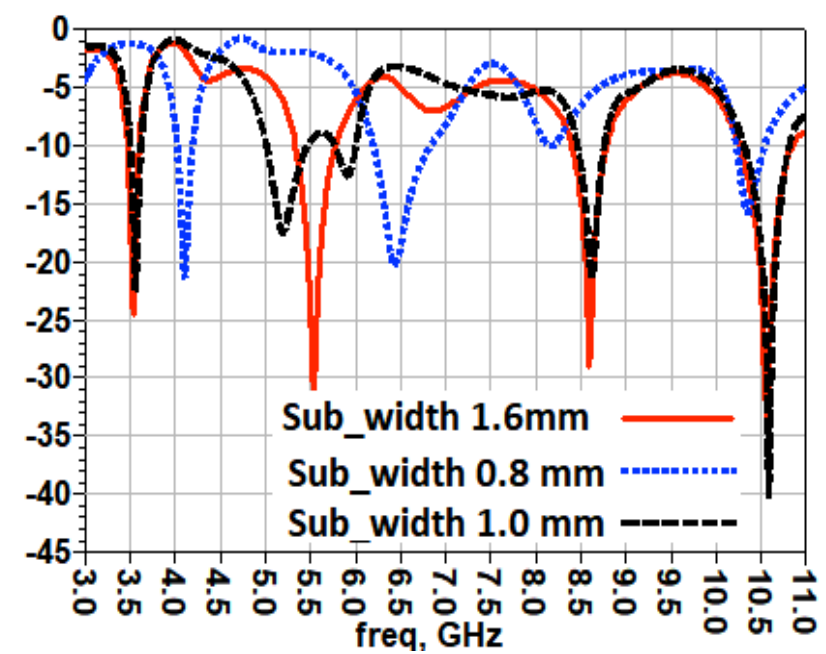

Fig. 4. The Simulated S11-Parameter of Proposed Antenna With Substrate width $(\mathrm{t})$ of : $0.8 \mathrm{~mm}, 1.2 \mathrm{~mm}$, and $1.6 \mathrm{~mm}$.

The comparison of the measured and simulated S11 parameter (Return loss) of the multi-band planar antenna is depicted in Figure 6. It has resonated in multiple frequencies. The return loss results indicate that initially resonated because of the first two L-shaped slot radiator at $3.5 \mathrm{GHz}$ with $-25 \mathrm{~dB}, 5.5 \mathrm{GHz}$ with $-31 \mathrm{~dB}$. It can be observed from Figure 6 right arm, left arm and bottom strip is shifting the lower frequencies. Thus, it is resonated 3.5 $\mathrm{GHz}$ with $-25 \mathrm{~dB}, 5.5 \mathrm{GHz}$ with $-31 \mathrm{~dB}, 8.4 \mathrm{GHz}$ with -30 $\mathrm{dB}$ and $10.4 \mathrm{GHz}$ with $-34 \mathrm{~dB}$. 


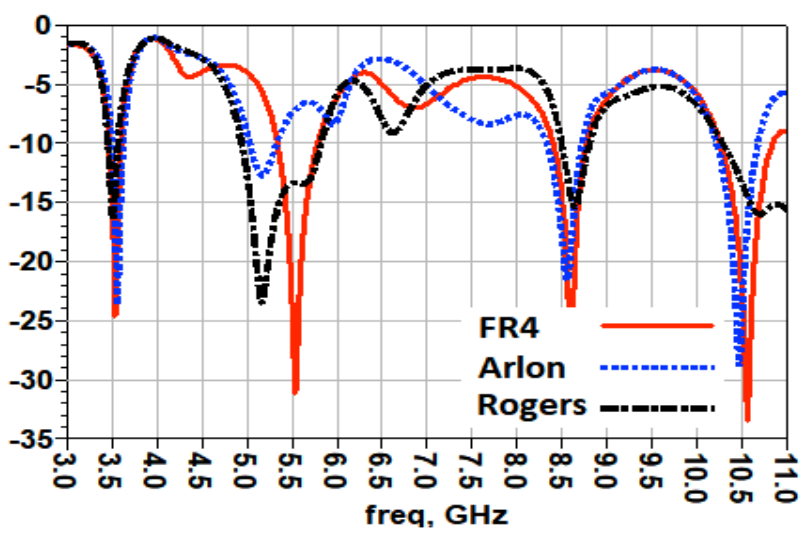

Fig.5 The Simulated S11-Parameters (Return loss) of Proposed Antenna with Different Types Substrate.

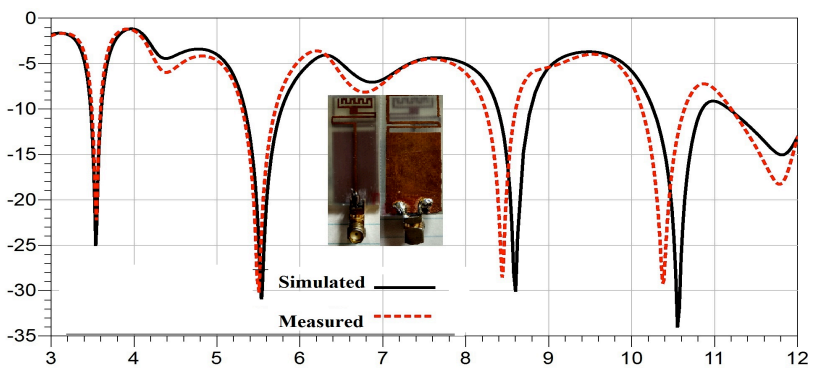

Fig. 6. The Simulated and Measured Return Loss of Proposed Gshaped Strip and L-shaped Grid Multiband Antenna.

From, the return loss of proposed structure appropriate for multiple wireless applications such as WiMAX, WLAN and Satellite applications. Though it has some discrepancies between simulated and fabricated return loss, it can observe that it has more than high bandwidth in almost all resonant frequencies. For all operating frequencies, perfect impedance matching is achieved. The simulated radiation pattern of the $\mathrm{C}$-shaped and L-shaped configuration for azimuth plane for $\theta=0,90^{\circ}(\mathrm{x}-\mathrm{y})$ and elevation plane for $\varphi$ $=0,90^{\circ}(\mathrm{y}-\mathrm{z})$ at various resonant frequencies, i.e., $3.5 \mathrm{GHz}$, $5.5 \mathrm{GHz}$, are shown in Figure 7 and Figure 8. It is observed that the omnidirectional radiation pattern is attained at all resonant frequencies in both $\mathrm{y}-\mathrm{z}$ and $\mathrm{x}-\mathrm{y}$ and planes.

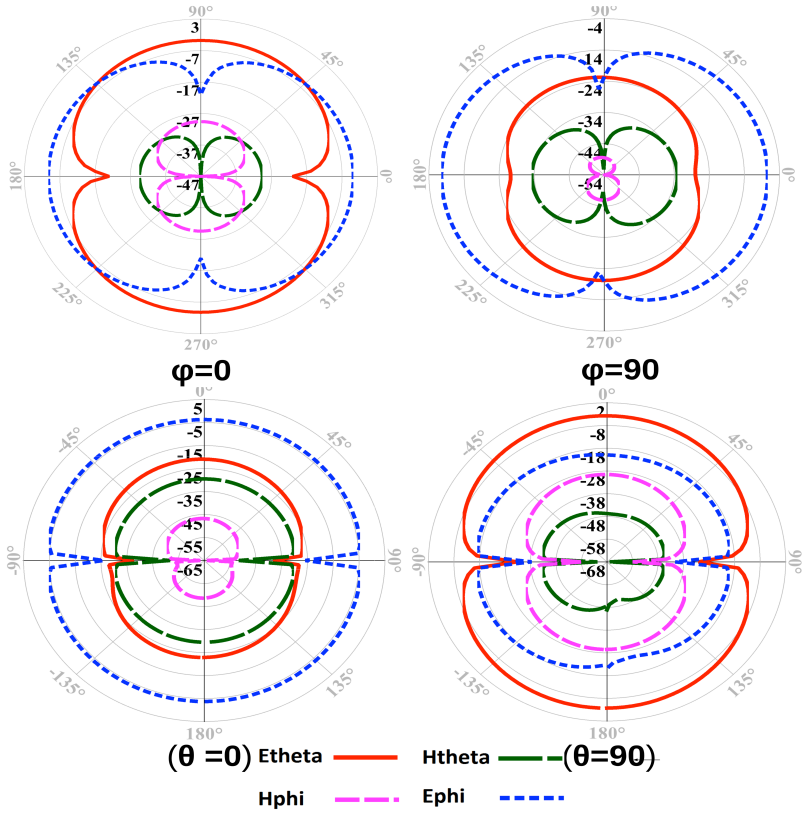

Fig. 7. Azimuth Plane For $\theta=0,90^{\circ}(\mathrm{xy})$ and Elevation Plane For $\varphi=0$, $90^{\circ}(\mathrm{y}-\mathrm{z})$ Radiation Pattern at $3.5 \mathrm{GHz}$.
It can also be perceived; there is almost no change in the radiation pattern of all resonant frequencies. Hence, it is providing proper radiation characteristics over the entire operating bands.

The measured gain of the proposed antenna is $4 \mathrm{dBi}$ at $3.5 \mathrm{GHz}, 4.5 \mathrm{dBi}$ at $5.5 \mathrm{GHz}, 4.5 \mathrm{dBi}$ at $8.4 \mathrm{GHz}$ and $4.8 \mathrm{dBi}$ at $10.4 \mathrm{GHz}$. The efficiency of the multi-band antenna is more than $85 \%$.

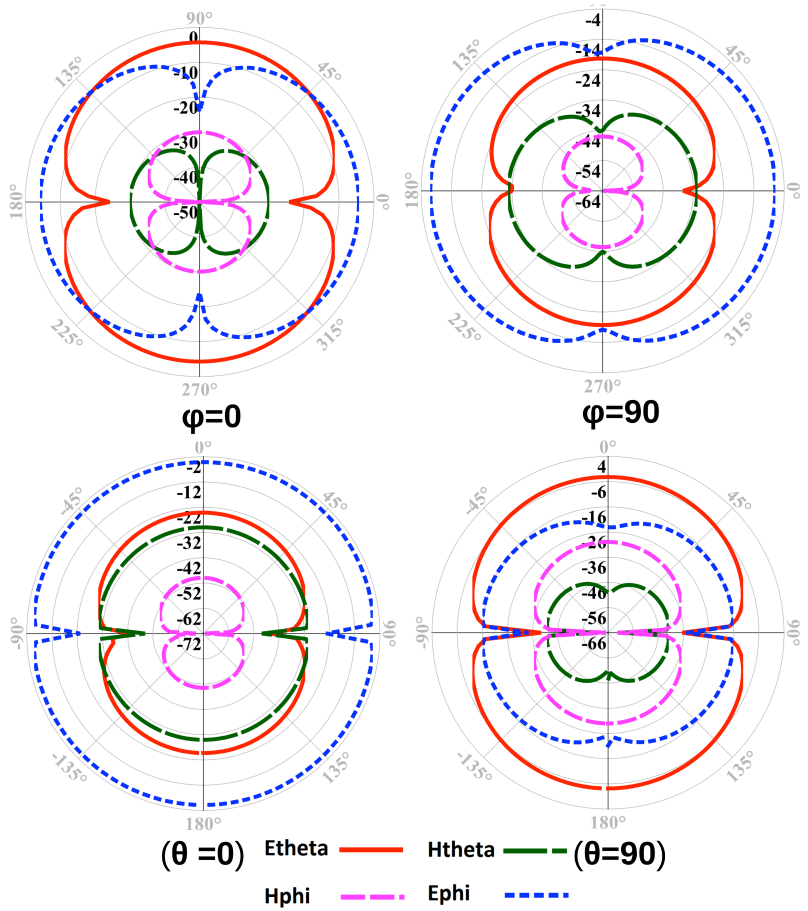

Fig. 8. Azimuth Plane For $\theta=0,90^{\circ}(x y)$ and Elevation Plane For $\varphi=0$, $90^{\circ}(\mathrm{y}-\mathrm{z})$ Radiation Pattern at $5.5 \mathrm{GHz}$.

Table 3. Measured VSWR of Proposed antenna.

\begin{tabular}{l|c}
\hline $\begin{array}{l}\text { Resonant frequency } \\
\text { (GHz) }\end{array}$ & Measured VSWR \\
\hline 3.5 & 1.8 \\
5.5 & 1.35 \\
8.4 & 1.52 \\
10.4 & 1.19 \\
\hline
\end{tabular}

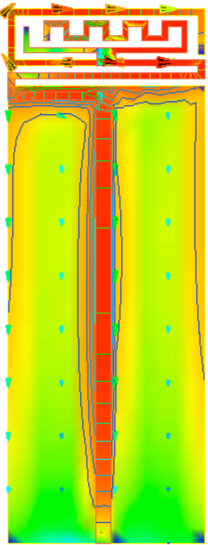

(a)

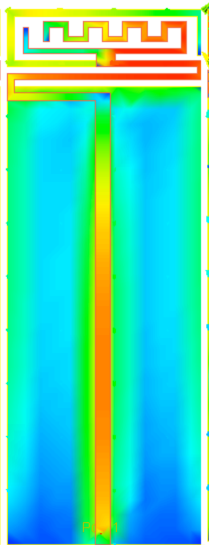

(b)

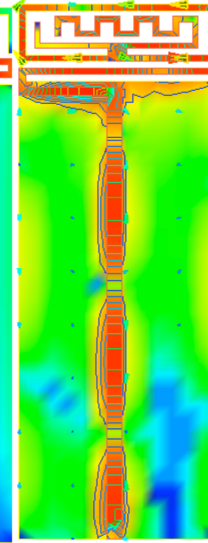

(c)

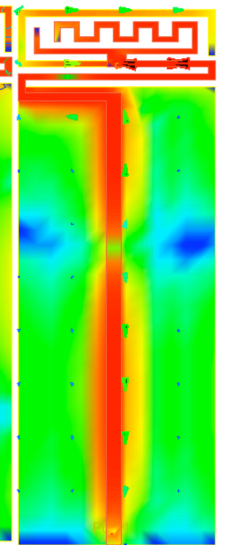

(d)
Fig. 9.Surface current distribution of Proposed C-shaped and L-shaped Meander Grid ntenna at $3.5 \mathrm{GHz}, 5.5 \mathrm{GHz}$, and 8.4 and $10 \mathrm{GHz}$.

Therefore, the proposed antenna is Multiband a good radiator. It indicates that it has VSWR of $<2$ for at all operating frequencies and that is listed in Table 3. 
The surface current of the suggested configuration at 3.5 $\mathrm{GHz}, 5.5 \mathrm{GHz}$, and $8.4 \mathrm{GHz}$ is presented in Figure 9. It is perceived that current equivalently circulated along the surface of the L-shaped strip (radiating element), C-shaped and ground plane at all resonant frequencies. The maximum current density is witnessed in the upper portion of the antenna because the L-shaped covered by $\mathrm{C}$-shaped and feed line of the antenna, but average current distribution is available at the ground plane of the proposed antenna for all resonant frequencies. It can be proved from radiation pattern and surface current; Also the ground structure contributed to radiation.

\section{Conclusion}

A multi-band C-shaped and L-shaped meander strip antenna have been fabricated for WiMAX, WLAN, and Satellite applications. The folded C-shaped and L-shaped meander strip configuration are employed to reduce the dimension of the antenna that is printed on the double the side of FR-4 Substrate with thickness $1.6 \mathrm{~mm}$. The proposed dimensions of the antenna are $30 \mathrm{~mm} \times 17.9 \mathrm{~mm} \times 1.6 \mathrm{~mm}$. The simulated and measured results were demonstrated. It is perceived that the suggested antenna structure has approximately omnidirectional radiation pattern characteristics and high bandwidth accomplished for all resonant frequencies. The bandwidth performance is optimized via mutual coupling between the upper part of the radiators and ground. The measured gain of the suggested antenna is $4 \mathrm{dBi}$ at $3.5 \mathrm{GHz}, 4.5 \mathrm{dBi}$ at $5.5 \mathrm{GHz}, 4.5 \mathrm{dBi}$ at $8.4 \mathrm{GHz}$ and $4.8 \mathrm{dBi}$ at $10.4 \mathrm{GHz}$. Hence, the fabricated Cshaped and L-shaped meander Strip multi-band planar antenna is perfectly suitable for multiband wireless applications.

This is an Open Access article distributed under the terms of the Creative Commons Attribution License

\section{References}

[1] Y. Cui, L. Yang, B. Liu, R. Li, Multiband planar antenna for LTE/GSM/UMTS and WLAN/WiMAX handsets, IET Microwaves, Antennas Propagation 10 (5) (2016) 502\{506. doi:10.1049/ietmap.2015.0545.

[2] W. Lee, Y. K. Hong, J. Park, M. Choi, J. Lee, I. S. Baek, N. P. Hur, W. M. Seong, Low-profile multiband ferrite antenna for telematics applications, IEEE $\begin{array}{llll}\text { Transactions on } & \text { Magnetics } & & \end{array}$ doi:10.1109/TMAG.2016.2535381

[3] Y. Yang, Q. Chu, C. Mao, Multiband MIMO antenna for gsm, DCS, and LTE indoor applications, IEEE Antennas and Wireless Propagation Letters $15 \quad$ (2016) $1573\{1576$. doi:10.1109/LAWP.2016.2517188.

[4] D. Guo, K. He, Y. Zhang, M. Song, A multiband dual-polarized omnidirectional antenna for indoor wireless communication systems, IEEE Antennas and Wireless $\begin{array}{llll}\text { Propagation Letters } & 16 \quad \text { (2017) }\end{array}$ 290\{293.doi:10.1109/LAWP.2016.2573840

[5] L. A. Shaik, C. Saha, J. Y. Siddiqui, Y. M. M. Antar, Ultrawideband monopole antenna for multiband and wideband frequency notch and narrow band applications, IET Microwaves, Antennas Propagation10 (11) (2016) 1204\{1211. doi:10.1049/ietmap.2016.0063.

[6] I.B. Trad, H. Rmili, J. M. Floch, W. Zouch, M. Drissi, Planar square multiband frequency reconfigurable microstrip-fed antenna with quadratic Koch-island fractal slot for wireless devices, Microwave and Optical Technology Letters $57 \quad$ (1) (2015) $207\{212$. doi: $10.1002 /$ mop. 28815 .

[7] R. Li, B. Pan, J. Laskar, M. M. Tentzeris, A compact broadband planar antenna for GPS, DCS-1800, IMT-2000, and WLAN applications, IEEE Antennas and Wireless Propagation Letters 6(2007)25 \{27.doi:10.1109/LAWP.2006.890754.

[8] S. Khajepour, M. S. Ghaffarian, G. Moradi, Design of novel multiband folded printed quadripolar helical antenna for
GPS/WLAN applications, Electronics Letters 53 (2) (2017) $58\{60$. doi:10.1049/el.2016.3889.

[9] A. Sharma, P. Ranjan, R. K. Gangwar, Multiband cylindrical dielectric resonator antenna for WLAN/WIMAX application, $\begin{array}{lllll}\text { Electronics } & \text { Letters } & 53 & \text { (3)(2017) } & 132\{134 .\end{array}$ doi:10.1049/el.2016.3548.

[10] J. H. Lu, W. C. Chou, Planar dual L-shaped monopole antenna with the multiband operation for IEEE 802.16e, IEEE Antennas and Wireless Propagation Letters9 (2010) 1006-1009. doi:10.1109/LAWP.2010.2087003.

[11]D. Guo, K. He, Y. Zhang and M. Song, "A Multiband DualPolarized Omnidirectional Antenna for Indoor Wireless Communication Systems," in IEEE Antennas and Wireless Propagation Letters, vol. 16, pp. 290-293, 2017. doi: 0.1109/LAWP.2016.2573840A.

[12]C. Mao, S. Gao, Y. Wang and B. Sanz-Izquierdo, "A Novel Multiband Directional Antenna for Wireless Communications," in IEEE Antennas and Wireless Propagation Letters, vol. 16, pp. 1217-1220, 2017.

doi: 10.1109/LAWP.2016.2628715.

[13]C. Mao, S. Gao, Y. Wang and B. Sanz-Izquierdo, "A Novel Multiband Directional Antenna for Wireless Communications," in IEEE Antennas and Wireless Propagation Letters, vol. 16, pp. 1217-1220, 2017.

doi: 0.1109/LAWP.2016.2628715A.

[14]J. Dong, X. Yu and L. Deng, "A Decoupled Multiband DualAntenna System for WWAN/LTE Smartphone Applications," in IEEE Antennas and Wireless Propagation Letters, vol. 16, pp. 1528-1532, 2017. doi: 10.1109/LAWP.2017.2647807

[15]H. Wen, Y. Qi, Z. Weng, F. Li and J. Fan, "A Multiband DualPolarized Omnidirectional Antenna for 2G/3G/LTE Applications," in IEEE Antennas and Wireless Propagation Letters, vol. 17, no. 2, pp. 180-183, Feb. 2018. doi: 10.1109/LAWP.2017.2778761 